\title{
Biological therapy of traditional therapy-resistant adult-onset Still's disease: an evidence-based review
}

This article was published in the following Dove Press journal:

Therapeutics and Clinical Risk Management

\author{
Sha Zhou* \\ Jianjun Qiao* \\ Juan Bai \\ Yinhua Wu \\ Hong Fang
}

Department of Dermatology, The First Affiliated Hospital, College of Medicine, Zhejiang University, Hangzhou, Zhejiang, People's

Republic of China

*These authors contributed equally to this work

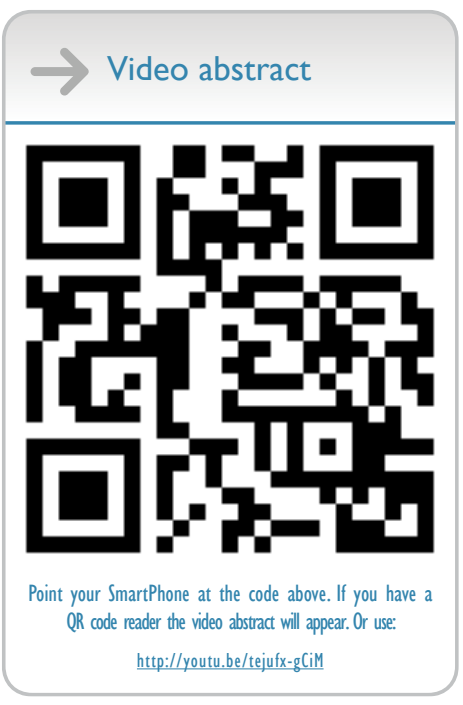

Correspondence: Hong Fang

Department of Dermatology, The First Affiliated Hospital, College of Medicine, Zhejiang University, No 79 Qingchun Road, Hangzhou 310003, People's

Republic of China

Tel +8657l 87236385

Email fanghongzy@zju.edu.cn
Background: Biotherapy is becoming increasingly important in the treatment of adult-onset Still's disease (AOSD). The aim of our study was to evaluate the efficacy and safety of biological therapy for AOSD resistant to traditional therapy.

Patients and methods: Database of Library of Congress, the PubMed, and Web of Science Core Collection were used to retrieve relevant articles published in English language until March 2017. Only studies published in English language were included, and the additional references quoted in these articles were also checked. Articles concerning the efficacy and safety of all the biotherapies in refractory AOSD were evaluated.

Results: There were 112 articles available in total; 422 AOSD patients were given at least one biologic. We found that 293 patients (69.43\%) had received TNF- $\alpha$ blocking agents (infiliximab, etanercept, and adalimumab), 194 patients (45.97\%) were treated with IL-1 receptor antagonists (anakinra, rilonacept, and canakinumab), 163 patients $(38.63 \%)$ were given IL-6 inhibitor (tocilizumab), and 24 patients (5.69\%) received rituximab and abatacept. The efficacy of biological therapy and overall tolerance of biological therapy for refractory AOSD were good. Thirty two of 271 patients given anti-TNF- $\alpha$ therapies $(11.81 \%), 116$ patients receiving IL-1 inhibitors (65.54\%), 124 patients receiving tocilizumab $(76.07 \%)$, and 13 patients given other biological therapies (36.11\%) achieved remission. Side effects of biologic therapy were infections such as urinary tract infections and soft tissue abscess.

Conclusion: Our findings suggest that anakinra and tocilizumab may be good choices for the treatment of refractory AOSD considering the effectiveness and safety.

Keywords: adult-onset Still's disease, biological therapy, treatment, side effects, anakinra, toclizumab

\section{Introduction}

Adult-onset Still's disease (AOSD), first recognized and described in 1971, ${ }^{1}$ is a rare multisystem inflammatory disorder of unknown etiology and pathogenesis characterized by a sudden onset of high spiking fever, evanescent skin rash, arthritis or arthralgia, leukocytosis, and a characteristically elevated serum ferritin level. ${ }^{2}$ AOSD is still an uncommon disease with a low prevalence of 1 to 34 cases per 1 million people, and it is more common in females than in males. ${ }^{3}$

The precise etiology and pathogenesis of AOSD remain unknown despite decades of research. It is generally accepted that the incidence of AOSD was associated with high levels of some proinflammatory cytokines such as IL-1, IL-6, IL-18, TNF- $\alpha$, and IFN- $\gamma^{4}$

Therapy of AOSD is usually empirical. During the first stage, nonsteroidal antiinflammatory drugs and corticosteroids are prescribed. AOSD patients suffer from not achieving remission and adverse reaction to nonsteroidal anti-inflammatory drugs. ${ }^{5}$ Also, 
about $45 \%$ of the cases receiving corticosteroids resulted in patients suffering from steroid dependency. Then, diseasemodifying antirheumatic drugs (DMARDs) are generally considered the second-line drugs in AOSD treatment. ${ }^{6}$ As for those patients resistant to the first- and second-line drugs, studies have focused on biological agents as choice of therapy for such patients. Biologics targeting important inflammatory cytokines (eg, TNF- $\alpha$, IL-1, and IL-6) play a critical role in the treatment of refractory AOSD. ${ }^{7}$ Also, most AOSD patients have benefitted from the efficient biological therapies. ${ }^{8}$

In order to evaluate the effect and safety of biological therapy for the treatment of ASOD, we systematically reviewed the published English-language articles concerning the treatment of AOSD with biological drugs.

\section{Patients and methods}

This evidence-based review focuses on the use and effectiveness of biologics in the treatment of refractory AOSD.

We searched all the literature published before March 2017. Database of Library of Congress, the PubMed, and Web of Science Core Collection were used to retrieve relevant articles published in English language. The search strategy used a combination of terms: adult-onset Still's disease, AOSD, biological therapy, biologics, TNF- $\alpha$ inhibitor, IL-1 inhibitor, IL-6 inhibitor, IL-18 inhibitor, infliximab, etanercept, adalimumab, golimumab, anakinra, canakinumab, tocilizumab, abatacept, and rituximab. Only studies published in English language were included, and the additional references quoted in these articles were also checked. Articles concerning the efficacy and safety of all the biotherapies in refractory AOSD were evaluated.

\section{Results}

We searched 168 articles by using the search strategy. Fifty-six articles were excluded as they were non-English-language articles, reviews, and case reports focused on conventional therapies. One hundred and twelve papers concerning biotherapies for refractory AOSD were included in this review. Only one randomized study compared the efficacy of anakinra and traditional drugs in the treatment of AOSD patients. The remaining articles included 2 open-label clinical trials, 9 retrospective studies, 5 case series, and 95 case reports. Among the total 112 articles, 33 reports evaluated the efficacy and safety of TNF- $\alpha$ (adalimumab, $n=6$, etanercept, $n=16$, infliximab, $n=11$ ), 39 articles demonstrated the effectiveness of IL- 1 inhibitors (canakinumab, $n=4$, rilonacept, $n=1$, anakinra, $n=34$ ), 40 studies reported the efficacy and safety of IL-6 blocker (tocilizumab, n=40), and 8 articles reported the effectiveness of other biological therapies (abatacept, $n=2$, rituximab, $n=6$ ).
All the 422 patients who were diagnosed with AOSD met the Yamaguchi criteria ${ }^{9}$ or Fautrel criteria. ${ }^{10}$ All of these patients failed conventional therapies, including high-dose corticosteroids and immunosuppressive drugs. The included patients had received biological therapy at least once.

The mean age of the 422 included patients (female, $\mathrm{n}=269$, male, $\mathrm{n}=142$, not reported, $\mathrm{n}=9$ ) was 37 years (range: 16-80). The mean duration from AOSD onset to the start of biologic therapy was 62 months (range: $0.1-408$ ). The characteristics of these patients are summarized in Table 1 .

Two hundred and ninety-three patients (69.43\%) had received TNF- $\alpha$ blocking agents (infliximab, $n=100$, etanercept, $\mathrm{n}=154$, adalimumab, $\mathrm{n}=39), 194$ patients $(45.97 \%)$ were treated with anti-IL-1 (anakinra, $n=184$, canakinumab, $\mathrm{n}=6$, rilonacept, $\mathrm{n}=4), 163$ patients $(38.63 \%)$ were given tocilizumab, and 24 patients $(5.69 \%)$ had received rituximab 11 times and abatacept 13 times. As a result, 37 (infliximab, $n=20$, etanercept, $n=13$, adalimumab, $n=4)$ of $293(12.63 \%)$ patients received TNF- $\alpha$ blockers, 127 of 194 (65.46\%) patients were treated with anti-IL-1 agent, 124 of $163(76.07 \%)$ patients received tocilizumab, and 8 of 24 (33.33\%) patients received other biologics, and all these patients achieved remission. Three hundred and eighty-four patients (91.94\%) tapered steroids without relapse when they were given biologics.

Table I Summary of patient characteristics at the start of the biologics therapy

\begin{tabular}{|c|c|}
\hline Characteristics & Results \\
\hline Age at biologics start, median (range) (years) & $35(16-80)$ \\
\hline $\operatorname{Sex}(N)$ & $\begin{array}{l}\text { Female: } 269 \text {, male: } \\
\text { I42, unknown: } 9\end{array}$ \\
\hline $\begin{array}{l}\text { Duration from onset to the start of } \\
\text { biologics median (range) }\end{array}$ & $27(<I-163)$ \\
\hline Follow-up median (range) (months) & $13.5(<1-84)$ \\
\hline \multicolumn{2}{|l|}{ Symptoms } \\
\hline Fever & $N=281,68.7 \%$ \\
\hline Rash & $N=223,54.5 \%$ \\
\hline Sore throat & $\mathrm{N}=\mathrm{I} \mid 3,27.6 \%$ \\
\hline Arthritis/arthralgia & $N=303,74.1 \%$ \\
\hline Myalgia & $N=57,13.9 \%$ \\
\hline Serositis/pleuritis & $\mathrm{N}=62,15.2 \%$ \\
\hline Lymphadenopathy & $\mathrm{N}=90,22 \%$ \\
\hline Hepatosplenomegaly & $\mathrm{N}=77,18.8 \%$ \\
\hline Leukocytosis median (range) $\left(10^{9} / \mathrm{L}\right)$ & $\begin{array}{l}\mathrm{N}=198,48.8 \% \\
16.4(10.2-96.0)\end{array}$ \\
\hline ESR median (range) $(\mathrm{mm} / \mathrm{l} \mathrm{h})$ & $\begin{array}{l}\mathrm{N}=26 \mathrm{I}, 63.8 \% \\
72(4-\mathrm{I} 44)\end{array}$ \\
\hline CRP median (range) ( $\mu \mathrm{g} / \mathrm{dL})$ & $\begin{array}{l}\mathrm{N}=262,64.06 \% \\
\text { II.I }(2.3-40)\end{array}$ \\
\hline Hyperferritinemia median (range) (mg/dL) & $\begin{array}{l}N=193,47.19 \%, 3,875 \\
(500-155,000)\end{array}$ \\
\hline
\end{tabular}

Abbreviations: CRP, C-reactive protein; ESR, erythrocyte sedimentation rate. 
Most of the reported adverse events of biotherapies were not severe during the treatment of AOSD. There were 20 adverse events caused by anti-TNF- $\alpha$ (adalimumab, $n=2$, infliximab, $n=6$, etanercept, $n=12$ ), 40 adverse events were caused by IL-1 antagonists (anakinra, $\mathrm{n}=39$, canakinumab, $\mathrm{n}=1$ ), and 40 adverse reactions were caused by IL- 6 inhibitor (tocilizumab, $n=40$ ). The main side effect in all cases was infection. There were also some life-threatening adverse events including macrophage activation syndrome (MAS), heart failure, and liver failure. The details about side effects during AOSD treatment are listed in Table 2.

\section{Discussion}

This report investigated the efficacy and safety of biologics in the treatment of refractory AOSD. It has been reported that activated T-cells and the overproduction of Th1 proinflammatory cytokines (TNF- $\alpha$, IL-1, IL-6, IL-18, and IFN- $\gamma$ ) play critical roles in the pathophysiology of AOSD. ${ }^{11}$ And the elevated cytokine level may be a result of a cascade of activations that TNF- $\alpha$ favors, activating IL-1, which stimulates the production of IL-6. ${ }^{12}$ Therefore, biological agents targeting these proinflammatory cytokines have been increasingly available since the first case received TNF agonist reported in 1998. ${ }^{13}$

The treatment of refractory AOSD is challenging. Not only an increase of steroid dosage and an addition of methotrexate are required but biologics are also needed. In our systematic review, we found TNF- $\alpha$ blockers (infliximab, adalimumab, and etanercept) were the most widely used biologics $(69.43 \%$ of patients) in the treatment of refractory AOSD. ${ }^{13,14}$ However, their effect (total: $12.63 \%$, infliximab: $6.8 \%$, adalimumab: $1.4 \%$, etanercept: $4.4 \%$ ) was the lowest compared with other biologics (eg, IL-1 antagonists, IL-6 inhibitors). TNF- $\alpha$ blockers should be switched from one to another, ${ }^{15-21}$ or changed to a different cytokine (IL-1, IL-6) receptor blocker to maintain disease remission. Though TNF- $\alpha$ plays an important role in a number of inflammatory disease such as rheumatoid arthritis and psoriasis, and the low effectiveness of TNF- $\alpha$ inhibitors may indicate that TNF- $\alpha$ is less critical in the pathophysiology of AOSD than IL-6 or IL-1.22

IL-1 and IL-6 receptor inhibitors were more likely to lead to a complete remission than TNF- $\alpha$ blockers. They could also normalize the acute-phase proteins, white blood cell count, erythrocyte sedimentation rate, and C-reactive protein level in refractory AOSD patients. ${ }^{23}$ Among all the 194 AOSD patients who received IL-1 inhibitors (anakinra, canakinumab, rilonacept), 127 patients (65.46\%) achieved disease remission. Additionally, an open and randomized study compared the efficacy of anakinra and DMARDs in refractory AOSD, and the results demonstrated that patients receiving anakinra showed more robust responses, although the results were not statistically significant. ${ }^{23}$ The patients had one problem with the drug and this was that anakinra had to be prescribed and injected daily. As for IL- 6 antagonist, 124 out of 163 patients (76.07\%) prescribed tocilizumab achieved

Table 2 Side effects reported on biological therapy of refractory AOSD

\begin{tabular}{|c|c|c|c|c|c|}
\hline Biologics & Rash & MAS & Infection & Others & Total \\
\hline Adalimumab & 1 & 2 & 0 & 0 & 3 \\
\hline Etanercept & 2 & 0 & $\begin{array}{l}3 \text { (I Listeria Meningoencephalitis, I Pneumocystis } \\
\text { jirovecii pneumonia, I thigh abscess) }\end{array}$ & 2 (I allergy; I shortness of breath) & 7 \\
\hline Infiliximab & 4 & 2 & $\begin{array}{l}3 \text { (I bacterial pneumonia, I hepatitis B virus, } \\
\text { I recurrent bronchitis) }\end{array}$ & $\begin{array}{l}3 \text { (I massive edema of the bilateral } \\
\text { periorbital region, I lupus rash + optic } \\
\text { neuritis, I cardiac failure) }\end{array}$ & 12 \\
\hline Anakinra & 18 & 0 & $\begin{array}{l}\text { I } 3 \text { (5 urinary tract infections, } 2 \text { soft tissue } \\
\text { abscess, I phalanx osteomyelitis, } \\
\text { I gastroenteritis with fever, I influenza A virus } \\
\text { infection of the upper respiratory tract, } \\
\text { I trachiobronchitis, } 2 \text { respiratory tract infection } \\
\text { by Pseudomonas aeruginosa, I herpes zoster) }\end{array}$ & $\begin{array}{l}8 \text { ( } 3 \text { mild leukopenia, I cardiac death, } \\
\text { I escape phenomenon, I myopathy, } \\
\text { I severe respiratory distress and } \\
\text { hemodynamic shock, I subacute liver } \\
\text { failure, } 2 \text { trombocytopenia) }\end{array}$ & 39 \\
\hline Canakinumab & 0 & I & 0 & 0 & I \\
\hline Tocilizumab & 0 & 2 & $\begin{array}{l}\text { I } 5 \text { ( } 4 \text { upper respiratory tract infection, } \\
2 \text { herpes zoster virus infection, I Epstein-Barr } \\
\text { virus infection, I dental infection, I acute } \\
\text { enterocolitis, I pyelonephritis, } 3 \text { bacterial } \\
\text { pneumonia, I urinary infection, I abscess in the } \\
\text { psoas muscle caused by Staphylococcus aureus) }\end{array}$ & $\begin{array}{l}23 \text { ( } 2 \text { facial swelling, } 2 \text { high blood } \\
\text { pressure, I deep vein thrombosis } \\
\text { and massive hematochezia, I chest } \\
\text { pain and chills, } 5 \text { increased alanine } \\
\text { aminotransferase levels, } 5 \text { leukopenia or } \\
\text { neutropenia, I liver failure, I liver Injury, } \\
2 \text { hyperlipidaemia, } 2 \text { hyperlipidemia, } \\
\text { I malignant melanoma) }\end{array}$ & 40 \\
\hline
\end{tabular}

Abbreviations: AOSD, adult-onset Still's disease; MAS, macrophage activation syndrome. 
disease remission. Additionally, tocilizumab has been observed to have a good effect in refractory AOSD patients, but is accompanied by life-threatening conditions like MAS. ${ }^{24}$ Both anakinra and tocilizumab could lead to rapid and sustained response and corticosteroid-sparing therapies. ${ }^{25}$

There is little knowledge about the efficacy of rituximab and abatacept on AOSD treatment. ${ }^{15,16}$ We cannot evaluate their efficacy, and so further studies are needed. ${ }^{25,26}$

With regard to the tolerance of biotherapies, the main side effects include mild to moderate skin rash and infections. However, attention should also be paid to the lifethreatening side effects such as MAS. On the one hand, the aberrant production of cytokines may lead to a series of associated disorders such as $\mathrm{MAS}^{27}$ and organ failure. ${ }^{28,29}$ On the other hand, treatment of ASOD with biologics would also lead to MAS. ${ }^{17,27,30-32}$ But there is no consensus about the mechanisms of MAS, and it may be triggered by a series of cytokines such as TNF- $\alpha$, IL-1 $\beta$, IL-6, IL-18, and IFN- $\gamma \cdot{ }^{33}$ The pathogenesis of MAS is still unknown. Perhaps the imbalance of the cytokine network caused by the blockade of one single cytokine would be the possible cause of biologics-associated MAS. ${ }^{27}$ This could be one reason why MAS could be treated with steroid-pulse therapy or concomitant nonselective immunosuppressive therapy. Therefore, further studies are needed to explain the pathogenesis of this interesting finding.

Only a few cases reported successful use of anakinra during pregnancy and breast-feeding in gestation. ${ }^{19,34}$ It may be feasible to use the biologics available like anakinra and infliximab during the early stage of the disease so that the side effects of high-dose steroids and DMARDs can be reduced. ${ }^{35}$

There are some limitations in our study. The selection bias could not be avoided. The retrospective nature of the study combined with the fact that it was a case series did not allow for the gathering of complete information on the patients. Cases published mainly described the patients with good responses when treated with biologics. The definition of disease remission was different in different reports. Additionally, there is no randomized, double-blind study to demonstrate the efficacy and safety of different biologics. ${ }^{7,15}$

Overall, biological agents are effective in the treatment of AOSD patients who are resistant to corticosteroids and DMARDs. IL-1 and IL-6 blockers are better than anti-TNF- $\alpha$ agents in efficacy and safety and also led to the achievement of greater success in the management of refractory AOSD. Among all the biologics mentioned in this review, anakinra and tocilizumab could serve as promising drugs that have the highest priority in the future treatment of refractory AOSD.
However, the data about the availability of abatacept is so limited that its tolerance cannot be evaluated. Further studies are required to assess the better use of both biologics in AOSD patients. If possible, randomized control trails should be conducted in the future to enable stronger evidence to be gathered about the effects and safety of biological therapy for AOSD patients.

\section{Conclusion}

Anakinra and tocilizumab would be promising drugs with the highest priority in the future treatment of refractory AOSD with good efficacy and safety.

\section{Acknowledgment}

This work was supported by the National Natural Science Foundation of China (81673045).

\section{Author contributions}

SZ and JQ was responsible for literature search of the studies and preparing the initial manuscript draft. HF was responsible for the study planning and completed manuscript revision. JB and YW searched and analyzed the literature and critically revised the manuscript. All authors contributed toward data analysis, drafting and critically revising the paper and agree to be accountable for all aspects of the work.

\section{Disclosure}

The authors report no conflicts of interest in this work.

\section{References}

1. Bywaters EG. Still's disease in the adult. Ann Rheum Dis. 1971;30(2): 121-133.

2. Al-Homood IA. Biologic treatments for adult-onset Still's disease. Rheumatology (Oxford). 2014;53(1):32-38.

3. Castaneda S, Blanco R, Gonzalez-Gay MA. Adult-onset still's disease: advances in the treatment. Best Pract Res Clin Rheumatol. 2016;30(2): 222-238.

4. Kadavath S, Efthimiou P. Adult-onset Still's disease-pathogenesis, clinical manifestations, and new treatment options. Ann Med. 2015;47(1): 6-14.

5. Gerfaud-Valentin M, Maucort-Boulch D, Hot A, et al. Adult-onset still disease: manifestations, treatment, outcome, and prognostic factors in 57 patients. Medicine (Baltimore). 2014;93(2):91-99.

6. Gerfaud-Valentin M, Jamilloux Y, Iwaz J, Seve P. Adult-onset Still's disease. Autoimmun Rev. 2014;13(7):708-722.

7. de Boysson H, Fevrier J, Nicolle A, Auzary C, Geffray L. Tocilizumab in the treatment of the adult-onset Still's disease: current clinical evidence. Clin Rheumatol. 2013;32(1):141-147.

8. Jamilloux Y, Gerfaud-Valentin M, Henry T, Seve P. Treatment of adult-onset Still's disease: a review. Ther Clin Risk Manag. 2015;11: 33-43.

9. Yamaguchi M, Ohta A, Tsunematsu T, et al. Preliminary criteria for classification of adult Still's disease. J Rheumatol. 1992;19(3):424-430.

10. Fautrel B, Zing E, Golmard JL, et al. Proposal for a new set of classification criteria for adult-onset still disease. Medicine (Baltimore). 2002;81(3):194-200. 
11. Choi JH, Suh CH, Lee YM, et al. Serum cytokine profiles in patients with adult onset Still's disease. J Rheumatol. 2003;30(11):2422-2427.

12. Fitzgerald AA, Leclercq SA, Yan A, Homik JE, Dinarello CA. Rapid responses to anakinra in patients with refractory adult-onset Still's disease. Arthritis Rheum. 2005;52(6):1794-1803.

13. Cavagna L, Caporali R, Epis O, Bobbio-Pallavicini F, Montecucco C. Infliximab in the treatment of adult Still's disease refractory to conventional therapy. Clin Exp Rheumatol. 2001;19(3):329-332.

14. Pouchot J, Arlet JB. Biological treatment in adult-onset Still's disease. Best Pract Res Clin Rheumatol. 2012;26(4):477-487.

15. Ostrowski RA, Tehrani R, Kadanoff R. Refractory adult-onset still disease successfully treated with abatacept. J Clin Rheumatol. 2011;17(6): 315-317.

16. Quartuccio L, Maset M, De Vita S. Efficacy of abatacept in a refractory case of adult-onset Still's disease. Clin Exp Rheumatol. 2010;28(2): 265-267.

17. Souabni L, Dridi L, Ben Abdelghani K, et al. Possible macrophage activation syndrome following initiation of adalimumab in a patient with adult-onset Still's disease. Pan Afr Med J. 2014;17:94

18. Ahmed O, Brahmania M, Alsahafi M, Alkhowaiter S, Erb S. Anakinra Hepatotoxicity in a patient with adult-onset still's disease. ACG Case Rep J. 2015;2(3):173-174.

19. Fischer-Betz R, Specker C, Schneider M. Successful outcome of two pregnancies in patients with adult-onset Still's disease treated with IL-1 receptor antagonist (anakinra). Clin Exp Rheumatol. 2011;29(6): $1021-1023$.

20. Lo Gullo A, Caruso A, Pipitone N, Macchioni P, Pazzola G, Salvarani C. Canakinumab in a case of adult onset still's disease: efficacy only on systemic manifestations. Joint Bone Spine. 2014;81(4):376-377.

21. Barsotti S, Neri R, Iacopetti V, et al. Successful treatment of refractory adult-onset still disease with canakinumab: a case report. $J$ Clin Rheumatol. 2014;20(2):121.

22. Aikawa NE, Ribeiro AC, Saad CG, et al. Is anti-TNF switching in refractory Still's disease safe and effective? Clin Rheumatol. 2011;30(8): $1129-1134$.

23. Nordstrom D, Knight A, Luukkainen R, et al. Beneficial effect of interleukin 1 inhibition with anakinra in adult-onset Still's disease. An open, randomized, multicenter study. J Rheumatol. 2012;39(10):2008-2011.
24. Tsuchida Y, Sumitomo S, Shoda H, Kubo K, Fujio K, Yamamoto K. Macrophage activation syndrome associated with tocilizumab treatment in adult-onset Still's disease. Mod Rheumatol. 2016:1-2.

25. Puechal X, DeBandt M, Berthelot JM, et al. Tocilizumab in refractory adult Still's disease. Arthritis Care Res (Hoboken). 2011;63(1): $155-159$.

26. Petryna O, Cush JJ, Efthimiou P. IL-1 Trap rilonacept in refractory adult onset Still's disease. Ann Rheum Dis. 2012;71(12): 2056-2057.

27. Watanabe E, Sugawara H, Yamashita T, Ishii A, Oda A, Terai C. Successful tocilizumab therapy for macrophage activation syndrome associated with adult-onset still's disease: a case-based review. Case Rep Med. 2016;2016:5656320.

28. Debiais S, Maillot F, Luca L, Buret J, Fautrel B, Renard JP. Efficacy of anakinra in a case of refractory Still disease. J Clin Rheumatol. 2008; 14(6):357-358.

29. Aly L, Iking-Konert C, Quaas A, Benten D. Subacute liver failure following anakinra treatment for adult-onset Still disease. J Rheumatol. 2013; 40(10):1775-1777.

30. Agarwal S, Moodley J, Ajani Goel G, Theil KS, Mahmood SS, Lang RS. A rare trigger for macrophage activation syndrome. Rheumatol Int. 2011; 31(3):405-407.

31. Mehta BM, Hashkes PJ, Avery R, Deal CL. A 21-year-old man with Still's disease with fever, rash, and pancytopenia. Arthritis Care Res (Hoboken). 2010;62(4):575-579.

32. Lequerre T, Quartier P, Rosellini D, et al. Interleukin-1 receptor antagonist (anakinra) treatment in patients with systemic-onset juvenile idiopathic arthritis or adult onset Still disease: preliminary experience in France. Ann Rheum Dis. 2008;67(3):302-308.

33. Schulert GS, Grom AA. Pathogenesis of macrophage activation syndrome and potential for cytokine-directed therapies. Annu Rev Med. 2015;66:145-159.

34. Berger CT, Recher M, Steiner U, Hauser TM. A patient's wish: anakinra in pregnancy. Ann Rheum Dis. 2009;68(11):1794-1795.

35. Moulis G, Sailler L, Astudillo L, Pugnet G, Arlet P. May anakinra be used earlier in adult onset Still disease? Clin Rheumatol. 2010;29(10): $1199-1200$
Therapeutics and Clinical Risk Management

\section{Publish your work in this journal}

Therapeutics and Clinical Risk Management is an international, peerreviewed journal of clinical therapeutics and risk management, focusing on concise rapid reporting of clinical studies in all therapeutic areas outcomes, safety, and programs for the effective, safe, and sustained use of medicines. This journal is indexed on PubMed Central, CAS,

\section{Dovepress}

EMBase, Scopus and the Elsevier Bibliographic databases. The manuscript management system is completely online and includes a very quick and fair peer-review system, which is all easy to use. Visit http://www.dovepress.com/testimonials.php to read real quotes from published authors. 